\title{
Sustainable Tourism Appliance in Destinations: An Overview of Ghodaghodi Lake Area in Far West Nepal ${ }^{1}$
}

\author{
Dr Pranil Kumar Upadhayaya
}

\begin{abstract}
Tourism is like a two edge sword which has both positive and negative consequences. Such a drift of tourism is found applicable in all destinations big or small, old or new. Nevertheless, the development intervention of new destinations with the sustainable tourism maxim from the very beginning can be much rewarding than a mass tourism induced mature destinations. Ghodaghodi Lake Area (GLA), a new tourist destination in Ghodaghodi Municipality (GM) of Kailali, extending to 2,726 hector of wetland with its designation as a Ramasar site, constitutes immense potential for prosperity through the sustainable tourism operation and management from its existing tourism offerings like lake viewing hiking, trekking, bird watching, and religious tourism activities. In this context, this paper aims to shed light on how a new destination like GLA is embedded with a number of challenges for sustainable tourism issues and what can be its remedy from sustainable tourism perspective. Developed through mix methods (qualitative and quantitative) of research, this paper has embedded its findings with the four progressive theoretical models (advocacy, cautionary, adaptability, and knowledge based platforms) as sustainable tourism. The poorly equipped infrastructures, lack of planned development activities, meager institutional capacity, and inadequate marketing have been pointed out as the drawback. This paper recommends that the formulation of a holistic plan of actions in the form of tourism master plan consisting of a self sustaining revenue model and its sincere application is the bottom-line to address sustainable tourism appliance challenges.
\end{abstract}

Key words: Ghodaghodi Lake area, sustainable tourism, destination operation management, prosperity through tourism

\section{Introduction}

The holistic definition of tourism elucidates it as, 'the activities of a man away from his usual habitat, the impacts that both he and the industry have on the host's socio-cultural, economic and physical environments and the responses of the industry to his needs (Jafari, 1977, p. 8).' Linking this definition of tourism with its growth based scenario, it is evident that tourism is one of the largest and fastest growing economic sectors in the world today. The rapid advancement of air transportation and information technology has speedily contributed for mass tourism in today's world. The exponential growth in the number of tourists from 25 million in 1950 to 1.4 billion in 2018 with 55 fold increases indicates it as one of the most remarkable economic phenomena in present peace time. The rapid growth of tourism today is one of the greatest success stories in $21^{\text {st }}$ century. As per United Nations World Tourism organization (UNWTO), total export earnings from international tourism reached USD 1.7 trillion in 2018, or almost USD 5 billion a day on average (UNWTO, 2019).

Tourists from round the world started to come to Nepal since 1950s. The commencement of international travels to Nepal with the summiting of world's highest mountains like Annapurna (1950), Everest (1953), Dhaulagiri (1960) and so on, and the growth in tourist arrival as stated 30 fold in 6 decades in 2018 to 1,173,072 have remained positive signals. Even through the size of international tourist arrivals to Nepal is smaller but it has increased continuously since 1950s except some notable interruptions. Such interruptions were in 1990 during democratic movement, between 1996 - 2006 armed conflict, and devastating earthquakes in April and May 2015. With notable economic indicators (e.g., international tourist arrivals 1,173,072, revenue USD 703.17 million, direct and indirect jobs 1,051,000, average spending by per visitor per day USD 44.00, and contribution to GDP 7.9 percent) in 2018, Nepalese tourism sector has the ability to be a development, empowerment and good-governance tool for Nepal (MoCTCA, 2019).

Whether national or international, tourism is a complex, multifaceted, multi-layered, and sophisticated sector with multidisciplinary fields. The rapid growth in tourist arrivals, with increase in economy, employment and general rise on the living standard of people in the world, has been also increasingly deteriorating destinations environment, overwhelming negative effects in origin socio-culture, and unfavorable economic effects on the host community. This has globally necessitated the appliance of sustainable tourism principles and practices in destinations to mitigate the negative consequences of mass tourism at international, national, regional and local arena.

\footnotetext{
${ }^{1}$ Cite this article as:

Upadhayaya, P. K. (2019). Contemporary Research: An Interdisciplinary Academic Journal, vol. 3 (1):

Pranil Kumar Upadhayaya, PhD, Senior Research Associate at NCCR

Email: pranilupadhayaya@gmail.com

Peer reviewed under the authority of CRAIAJ, academic journal of Ghodaghodi Multiple Campus, Kailali, Nepal. (C) 2019 Contemporary Research: An Interdisciplinary Academic Journal
} 
The Government of Nepal Ministry of Culture, Tourism and Civil Aviation's (MoCTCA) endorsed National Tourism Strategy Plan (NTSP, 2016-25) envisions the disbursement of tourism over the country by developing new destinations and tourism infrastructures in an equitable approach, while adding to the diversity of attractions (MoCTCA, 2016). MoCTCA's NTSP study team had identified a total of seven Tourism Development Areas (TDAs) as the development zones, or clusters, or tourism regions which are widely distributed throughout the country and focuses on opening relatively undeveloped areas. This team made assessment of integral factors of sustainable tourism planning while formulating NTSP. The NTSP's assessment included seven criteria like sustainability, infrastructure, potential, demand, diversification, social impact and poverty alleviation and government strategic priority. Each of the criteria was rated from 1 (as the lowest) to 5 (as the best). Ghodaghodi Lake Area (GLA) in Ghodaghodi Municipality (GM) (which is the focus of the article) has shown 5 in ratings for destination potential, diversification status, social impact and poverty alleviation and government strategic priority. However, TDA for Kailali scored lower both on demand ( 2 in ratings) and infrastructure ( 3 in ratings). Its causes are mentioned as the relative isolation, lack of adequate accessibility and poor marketing and promotion (MoCTCA, 2016; Upadhayaya, 2019a). Nevertheless, GLA is a highly potential for the development of tourism due to its strategic location at the mid of Bardia National Park to the East and Shuklaphanta National Park to the West.

There is immense opportunity to develop GLA as an important Bird and Biodiversity Areas (IBBAs) and an ecotourism destination. However, GLA is particularly embedded with a number of challenges (as its weaknesses) for sustainable tourism issues like poor and substandard infrastructures, lack of one door system for tourism related operation and management, lower investment on and return from tourism enterprises, lack of adequate touristic packages and market research based demands, over pollution (plastic wastage, poisoning, use of pesticides \& agro chemicals), poor waste and garbage management, overharvesting of fish, overgrazing, conversion of wetland and forest land (forest destruction) into other land use practices, weak technical capacity for wetland management and governance, and inefficient implementation of landscape and environmental conservation. The lack of a holistic plan of actions in the form of tourism master plan consisting of a self sustaining revenue model is the bottom-line to address all above challenges.

In aforementioned context, the planning and execution of conservation, responsible management and sustainable tourism development intervention of GLA along with natural, ecological, socio-economic and religious characteristics and values, can be traced as immensely significant. Realizing this necessity, GM had earlier approached the CD-Mun project ${ }^{2}$ with the request for technical support on tourism development. The municipality is already active to promote touristic sites/resources, especially the Ghodaghodi Lake. This article is the outcome of the first phase of assignment for the formulation of tourism master plan of GLA.

Methodologically, this assignment adopted participatory public-private cooperation practice of knowledge building to assess the present state of GM led Comprehensive Ghodaghodi Lake and Tourism Development Board (CGLTDB) that plans to act as the Destination Management Organization (DMO) and identify a sustainable business model with revenue and action plans for GLA. This article links with the four progressive theoretical models of tourism (advocacy, cautionary, adaptability, and knowledge based platforms) propounded by Jafar Jafari (1990 and 2005). It applies combined tools like desk review of relevant manuscripts, focus group discussions, site observations through hiking in and around GLA, and key informant interviews to gather information, In this context, this article brings information on sustainable tourism and its structural overview, importance of sustainable tourism appliance in building tourist destinations, sustainable tourism appliance in Nepal's national context, about GLA as a new tourist destination, sustainable tourism development status, perspective and challenges in GLA and conclusion with some recommendations for sustainable tourism appliance.

\section{Sustainable tourism and its literature review}

UNEP and UNWTO (2005, p. 11-12) define sustainable tourism as "tourism that takes full account of its current and future economic, social and environmental impacts, addressing the needs of visitors, the industry, the environment and host communities". The purpose of sustainable tourism is to make a balance between protecting the environment, maintaining cultural integrity, establishing social justice and promoting economic benefits meeting the needs of the host population in terms of improved living standards both in the short and long term. Sustainable tourism is envisaged as leading to management of all resources in such a way that economic, social and aesthetic needs can be fulfilled while maintaining cultural integrity, essential ecological processes, biological diversity, and life support systems. A key concern therefore, is the appropriate interaction between biodiversity conservation planning and tourism planning and development.

\footnotetext{
2 The project "Capacity Development of New Municipalities" (CD-Mun) is commissioned by German Federal Ministry for Economic Cooperation and Development (BMZ). The project aims at capacitating municipalities to implement the reforms of the municipal governance framework (territorial, functional, political) with a particular focus on service delivery and access of disadvantaged groups to municipal services
} 
Sustainability implies permanence, so sustainable tourism includes optimum use of resources, including biological diversity; minimization of ecological, cultural and social impacts; and maximization of benefits to conservation and local communities. Sustainable tourism also refers to the management structures that are needed to achieve this. It ensures that tourism developments are sustainable in the long term and, wherever possible, help in turn to sustain the areas in which they operate (Hugo, 1998; Shen, Hughey and Simmons, 2008; STN, 2007; Upadhayaya and Sharma, 2010).

Sustainable tourism as for other industries, has generally four interconnected benefiting aspects (figure 1); economical, environmental, socio-cultural, and educational.

Figure 1: Sustainable tourism framework with its interconnected benefiting aspects

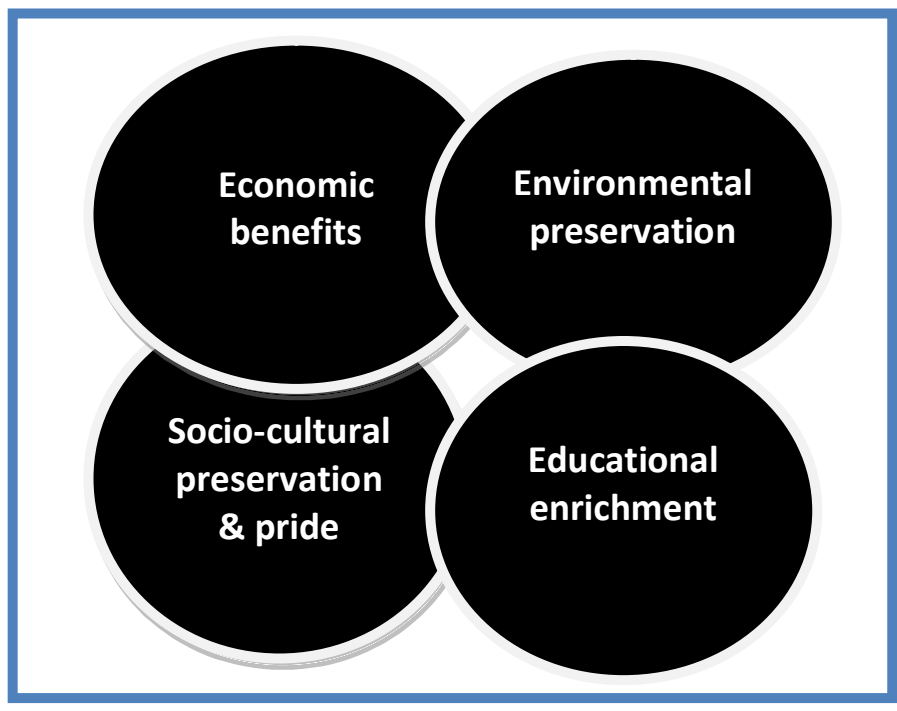

Source: Adapted from Upadhayaya and Sharma (2010) and Zolfani, Sedaghat, Maknoon, and Zavadskas (2015)

Economically, sustainable tourism benefits residents of destination areas where tourism operates. Travel businesses do their best to employ and train local people, buy local products, and use local services. From the view point of environment, sustainable tourism conserves resources. Environmentally aware travelers favor businesses that minimize pollution, waste, energy, energy consumption, water usage, landscaping chemicals, and unnecessary nighttime lighting (Bhatt, 2006; Bhatta, 2000). Sustainable tourism emphasizes the character of the locale assets like architecture, cuisine, heritage, aesthetics, and ecology. Tourism revenues in turn raise local perceived value of those assets. Being educational too, sustainable tourism is knowledge based and knowledge oriented. It is informative and great trips for both travelers and residents. Due to the aforementioned multitude of interconnected aspects, sustainable tourism is applicable in several forms of tourism as in figure 2 below.

Figure 2: Applicability of sustainable tourism in all forms and scales of tourism

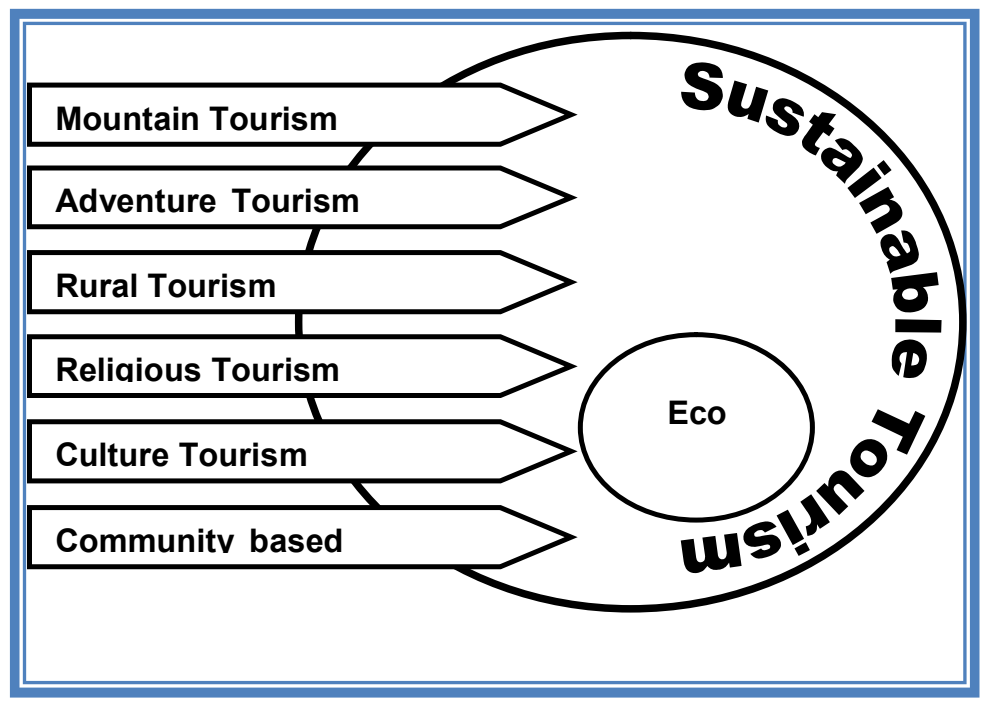

Source: Adapted from France (2006) 
One of the goals of sustainable tourism is Sustainable Destination Management (SDM). SDM integrates tourism with conservation, socio-economic development, religious and cultural enrichment, public, private and community partnership for destination development and sustainable infrastructure development. For SDM, sustainable tourism also refers to the management structures that are needed to achieve this.

\section{Sustainable tourism theory}

The four chronological platforms comprising the research focuses of various tourism writers with their evolutionary characteristics are appropriate to mention for the theoretical clarity of sustainable tourism (Weaver, 2006). These frameworks are also related with chronologically evolved concept of development with its four main schools of thought ${ }^{3}$. These platforms (figure 3) on thinking of tourism in relationship with its sustainability are described one by one.

Figure 3: Sustainable tourism theoretical models

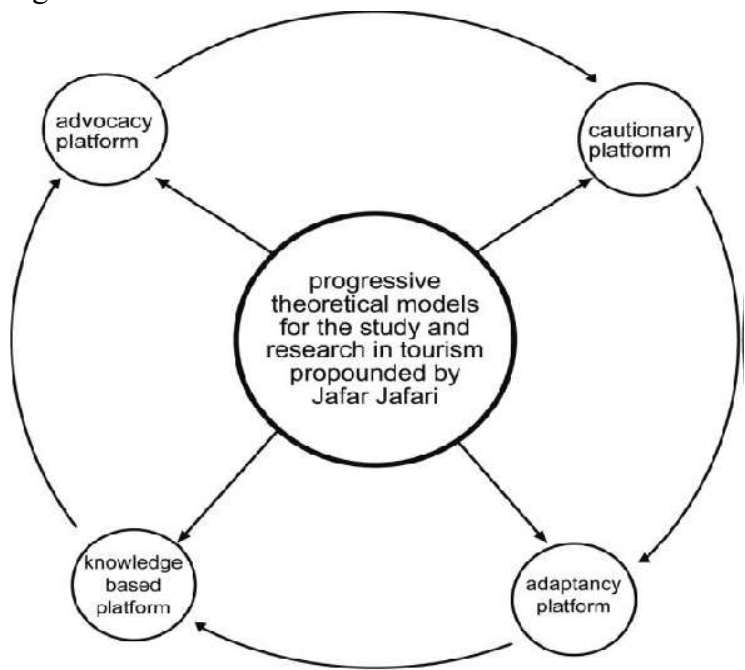

Source: Author's compilation based on Jafari (1990 and 2005)

Advocacy platform emphasizes the economic benefit of tourism and subscribes its development due to its constructive role in the national economy and subsequent promotion of peace-building. This platform appeared in the postwar period with pro-tourism perspective in the 1950s and 1960s. This platform touted for the newly independent but impoverished countries of the South, as a benign avenue to economic, socio-cultural and environmental development and benefits that would be sustained by an inexhaustible supply of tourism resources such as beaches, local culture and scenery.

Relating with the dependency theory of development, the emergence of cautionary platform in the late 1960s and early 1970s warns against the consequences (negative consequences) of tourism development both in economic and noneconomic areas which are conflict-sensitive. Various studies (Lea, 1996; Richter, 1986; Shackley, 1998; and Sharma, 2012) reveal about such sensitiveness of tourism among the complex relationships of various stakeholders in the host society moreover those destinations which are less developed where negative impacts became increasingly evident.

With the debates between the advocacy and cautionary platforms and two positions for and against tourism laid out consequently, the synthesizing adaptancy platform emerged in the early 1980s, examines alternative forms of tourism development that would maximize benefits and minimize costs (Jafari, 2005; and Shen et al., 2008). This platform favors new forms of tourism (e.g. pro-poor and community-based tourism, eco tourism and justice tourism), which are responsive to host communities, employ locals, utilize local resources, apply 'sharing or co-operative power relation', respect local cultures, involve local communities in tourism, and be alert to hosts' natural, socio-cultural and man-made (heritage) environments.

According to Jafari (2005), the knowledge-based platform is the accumulation of several factors that gave rise in the late 1980s and 1990s. This platform has emerged to complement the general focus of the advocacy and cautionary platforms on consequences of tourism and refined the focus of the adaptancy platform on forms of development. Jafari (2005, p. 2) in relation to the position of the all four platforms at the present context states: "with these four platforms, generalizing the tendencies of their areas, appeared in the foregoing order, they did not replace one another. Indeed, they are all present today, echoing the voices by which they are characterized, with the last one being responsible for enhancing the academic position of tourism worldwide". The review of Jafari's progressive models summarizes that the notion on the role of tourism for peace can be viewed from sustainability perspective.

\footnotetext{
${ }^{3}$ E.g. Modernization, dependency theory, alternative development, and sustainable development. See Shen, Hughey, and Simmons (2008) for details.
} 


\section{Importance of sustainable tourism appliance in building destinations}

A number of studies (Kunwar, 2006; Mowforth and Munt, 1998; Nepal, 2003; Timothy and Boyd, 2015; UNEP and UNWTO, 2005; UNWTO, 2007; Upadhayaya, 2011) and tourism plan and project actions reveal that tourism, if managed and operated in sustainable manner, can have multitude of positive impacts in a destination which can be categorically mentioned below.

\section{Positive significance of sustainable tourism on society and culture}

The socio-cultural impacts of tourism described here are the effect on host communities of direct and indirect relations with tourists, and of interaction with the tourism industry. The cross-cultural interactions between guests and hosts may have following influences in society and culture of host communities.

- Sustainable tourism brings about positive changes in value systems, behavior and thereby strengthens and prides indigenous identify.

- Constructive changes may occur in community structure, family relationships, collective traditional life styles, ceremonies and morality.

\section{Positive significance of sustainable tourism on environment}

The environment is tourism's resources. It is environment or rather the experience or enjoyment of it, that the tourism industry promotes a sells. The quality of the environment both natural and man-made is essential to tourism. However, tourism's relationship with the environment is positively correlated through ecotourism. Such a form of tourism discourages the excessive use and distribution of environmental resources due to the construction of infrastructures, superstructures and tourism facilities including hotels, restaurants, shops, golf courses and marinas. Environmentally friendly tourism supports to protect the ecology and ecosystem and the destructions of the environmental resources on which tourism depends.

\section{Positive significance of sustainable tourism on economy}

There are many hidden costs to tourism which is not sustainable, which can have critical economic effects on the host community. On its contrary, sustainable tourism has enormous positive impacts. Few of such impacts are mentioned as follows.

- The sustainable tourism is economically viable and it is inclined to prevent leakages ${ }^{4}$ through taxes, wages to hired employees from foreign nations, carrying of profits by multinational companies and import purchase.

- The appliance of sustainable tourism is against the economic leakage that can occur on import of foods and drinks, inventories and fixed equipments. There is general trend of this leakage by $40-95 \%$ on gross earnings of developing countries.

- Sustainable tourism is preventive towards the export leakages that are found occurring globally through the unsustainable mass tourism due to the investments of multinational companies and investors on tourism products, infrastructures and facilities in a situation where the least developed but potential tourist destinations are not able to afford required investments of capital and technology.

- The global perspective of sustainable tourism is associated with its potentiality of poverty eradication and peace building through generation of employment, income, foreign exchange earnings, etc. UNWTO, with its belief that tourism can be effectively used as a force for the elimination of global poverty, has made a commitment to contribute to the United Nations Millennium Development Goals through a new programme known as Sustainable Tourism- Eliminating Poverty (ST-EP) in 2003.

\section{Sustainable tourism appliance in Nepal's national context}

The process of tourism development in Nepal through the strategy of economic planning was initiated through the very first national five-year development plan (1956-70) to promote tourism in the country and institutionalize it as a source of foreign currency earning and employment within the country. There has been a period of almost five decade of planning with a total of fourteen periodical plans and a number of thrusts in inconsistent manners (NPC, 2019).

\footnotetext{
${ }^{4}$ According to the UNEP (United Nations Environment Programme), for every 100 \$ spent by a tourist on a holiday to a developing country, only $5 \$$ remain in the host community. That's a tourism leakage of $95 \%$. See https://beachmeter.com/tourism-leakage-does-your-money-contribute-locally/ for more information
} 
The brief overview of the tourism development plans of Nepal finds that the government was pioneer to develop tourism in an integrated approach as the essence of sustainability. Realizing the importance of public private partnership for integrated development of tourism, a review of the Nepal Tourism Master Plan in 1984 recommended establishment of a separate autonomous semi public (in association with private sector) Nepal Tourism Promotion Board. Then, with the support of UNDP's Partnership for Quality Tourism Project, The Nepal Tourism Board (NTB) as an autonomous national tourism organization, the first and only of its kind in South Asia, was designed as a partnership between the Government of Nepal and the private sector tourism industry of Nepal that came in effect from January 1, 1999. It was just in the year 1996 when the armed conflict began, a yearlong national tourism campaign for 1998 as "Visit Nepal Year (VNY) 1998" with the central theme "a sustainable habit through sustainable tourism" in association with private sector of tourism industry was officially declared.

Though there is deficiency on the execution of sustainable tourism development plans and policies in Nepal, nevertheless there are few notable examples of sustainable tourism development endeavors in past. Such endeavors from the economic aspect include the following (Hummel, Oostveen, and Stoer, 2003; Upadhayaya, 2011):

- Branding of Nepal as ' Naturally Nepal: Once is Not Enough' by Nepal Tourism Board.

- Successful completion of 'Tourism for Rural Poverty Alleviation Programme' during 2001-05 targeting the upliftment of socio-economically deprived people with special emphasis to women in six districts of Nepal. It has three major objectives with a view to sustainable development tourism in Nepal as follows.

- Opening of foreign investment in travel, trekking, rafting and pony trekking sub sector of tourism.

- Commencement of a project titled 'Marketing Assistance for Sustainable Tourism Products Development (MAST NEPAL)' during 2006-07

From the environmental aspect, the mandatory application of the provision of garbage management to be applied by expedition team while mountaineering in Nepal during the beginning of $21^{\text {st }}$ century is notable.

A review of Nepal national tourism policy 2009 reveals gaps on a number of issues related to sustainable tourism development in Nepal. It necessitates revising the existing tourism policy with the some concrete provisions of sustainable tourism action plans like balancing between conservation and tourism development, defining sustainable tourism national indicators, provisioning research and database to measure the economic and social benefits of tourism, laying down sustainable tourism certification policy, and focusing on the development of community based ecotourism in small touristic places. Some other provisions included implementing integrated development of tourism only after the application of sustainable tourism development tools like carrying capacity analysis and environment impact analysis, ensuring social, cultural and environmental sustainability of tourism projects implemented with the assistance of external partners, and building massive awareness to create knowledge about the utilities of sustainable tourism practices, etc. (Dhakal, Khadka and Grandon, 2007; MoCTCA, 2009; Sharma, and Choegyal, 2007; Upadhayaya and Sharma, 2010; and Upreti, Sharma, Upadhayaya, Ghimire, and Iff, 2013).

\section{Ghodaghodi lake area: A potential destination for sustainable tourism}

Ghodaghodi Lake Area (GLA) is one of the newer tourist destinations in Nepal. It is one of the Important Bird and Biodiversity Areas (IBBA) lying in GM region in Kailali district in Sudurpashchim province:

Figure 4: GLA in Far west Nepal

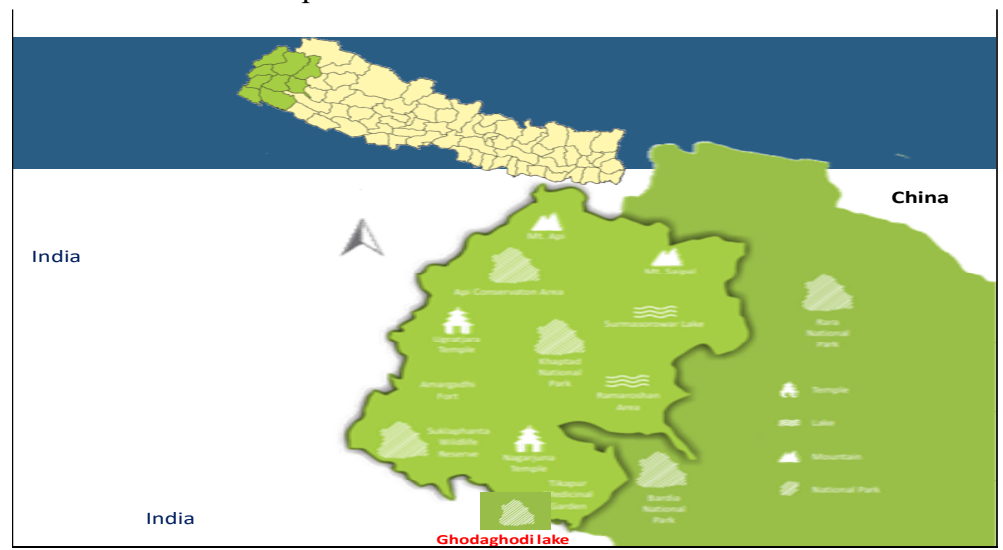

Source: Author 
Established in $2071 \mathrm{BS}$, GM covers total area of 354.44 square kilometer whose altitude ranges between 205 to $1470 \mathrm{~m}$. Its land cover type consists of forest 52.5 percent, degraded forest 3 percent grassland 1.8 percent, agriculture land 34.5 percent, highway/greenbelt 0.5 percent, sand/riverbed 1.6 percent, and lakes 6.1 percent (Far West, 2018).

As the largest natural freshwater lake system in Nepal's terrain with 60-70 percent tropical and subtropical deciduous forest cover, GLA is spread in 2,726 hector of wetland with many adjoining small lakes in GM. This lake area consists of 66 bigger and smaller lakes within the boundary of GM. The coverage of the GLA is wider from Mahendra highway on the south in Terai to the boarder of Chure Mountains on the north and Kandra river corridor on the west to Doda river corridor on the east (GM, 2074). GLA is also designated as a wetland of international importance under Ramsar Wetland Convention on $13^{\text {th }}$ August 2003. It is a potential destination for walking, hiking, trekking, horse riding and bird watching related activities. The outer circuit trip of GLA (that also touches to Chure/Shivalik range) covers 35 Kilometer of trekking route between Simtari to Lathuwa villages that passes via Maghi, Gaidakhera, Chilamchaur (Churia hill), Kedar (Churia hill), and Malika (Churia hill) in Ghodaghodi Municipality (GM). The inner circuit close around Ghodaghodi Lake (the core lake spot) trip offers 28 Kilometer of walk. There are a total of 33 small sized hotels, 1 community home stay and few individual home stays in GLA (DFO, 2073; GM and CGLTDB, 2018, Kailali DCC, 2018).

Figure 5: Demarcation map of GLA

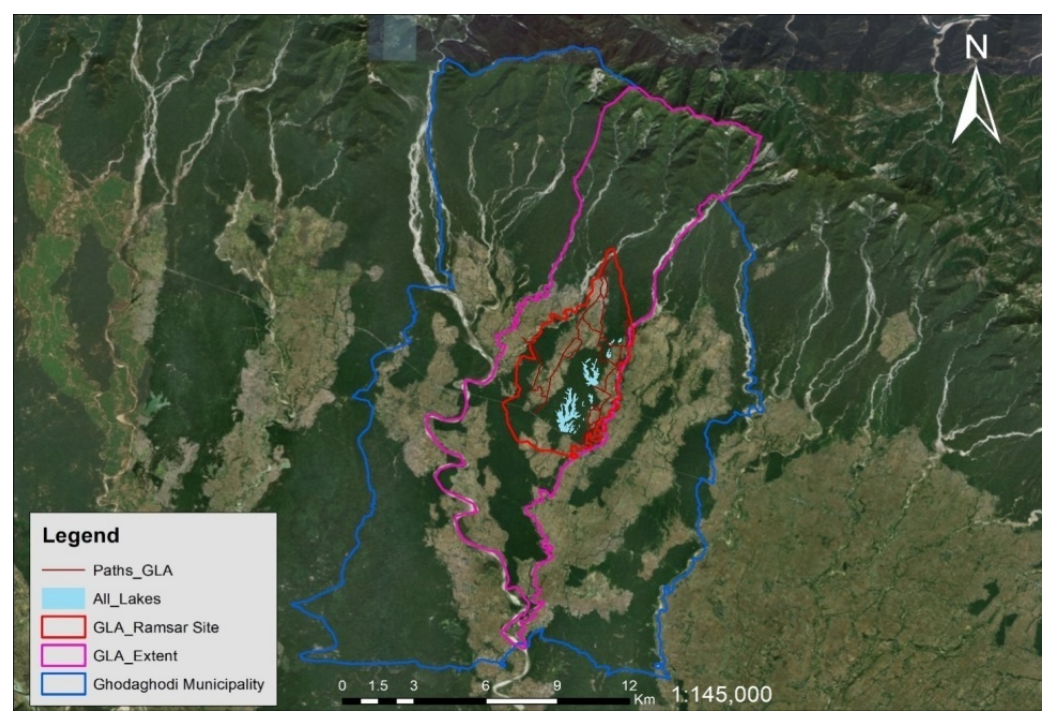

Source: Field survey

GLA is strategically located in the middle of Kailali surrounded by Bardagoriya Rural Municipality Area in East, Gauriganga Municipality in West, Chure Rural Municipality in North and Bhajani Municipality in South. Situated between Doda river on the east and Kandra river on the west originating both from Chure hills, the forest and wetlands of this lake is full of both aquatic and terrestrial biodiversity. It is the habitat for 34 species of mammals, around 31 species of fishes, 32 species of butterfly, 299 species of birds (migratory and residential), 450 species of plants, 11 species of snails, 7 species of reptiles, etc. GLA also functions as wildlife corridor between the Terai and the Churia hills. The lake system is important habitats for many floral faunal species that have global environmental significance. GLA area has good habitat for birds as more than 20,000 birds exist there and around one percent of birds from South Asia region seasonally arrive in the area. For these attributes, GLA is able to fulfill two out of eight indicators of Ramasar Declaration Iran. It is designated as a wetland of international importance under Ramsar Wetland Convention on $13^{\text {th }}$ August 2003. The three species of birds namely Common Moorhen, Spot-billed Duck and Cotton pygmy goose breeds only in Ghodaghodi Lake of Nepal. Hence, it is a destination which has potential to be declared as Nepal's first bird sanctuary subject to meeting some basic parameters for this category. The location of Ghodaghodi temple in this area possesses immense religious, cultural and spiritual value for the local indigenous Tharu communities and other communities like Magar, Chhetri, etc. in this region. The multicultural identity of GM with several indigenous flavors can be the asset for potential tourist destination (Joshi, 2018). At present, GLA has potential to be developed as a main destination due to a number of following attributes (Upadhayaya, 2019b).

- Greater geographical area coverage of this destination in approximately 9000 hector

- Interconnection of GLA with Chure Shivalik range on the north after the walk of a couple of hours

- Diversity of attractions from Tal (lake) to Himal and local culture of Terai and mountain landscape and potential for branding accordingly

- The deep rooted appearance of the unique attraction of Tharu culture 
- Location near to the western entry gate of Nepal [on the surface drive of just a couple of hours from Nepalese boarder like Trinagar (Dhangadhi) and Gaddhchowki (Mahendranagar]

- Destination site just beside Mahendra highway, Nepal's lifeline connecting West to East and vice versa

- Availability of organic and local food for incoming visitors

- Simplicity and rich hospitality nature of local hosts (Tharus, Magar, Brahmins, and Chettri)

However, it is recently recognized as an add-on destination which has little spill over benefits confined only in tour packages mostly combined with Dhangadhi, Shuklaphanta, Chisapani, Tikapur, etc.

There are following common expectations of local people on the productive sector of tourism from this wetland destination.

- Protection from encroachment through illegal cultivation, unsustainable harvesting of water for farmland irrigation from lake via water cannels)

- Conservation from agro chemicals, pesticides, fertilizer, plastic waste and zoning of core area

- Broadening socio-ecological benefits

- Strengthening lake basin management for the prosperity of lake area through a commonly accepted new model

- Building of lake based tourism infrastructures (walking trail all around the lake) for tourism

- Enhancement of economic opportunities through bird watching/eco tourism/green tourism/religious tourism/culture tourism and shift from traditional subsistence system for livelihood support to enterprises development

- Development eco trail (walking + cycling + pony trek) route with basic infrastructures like path safety, signage installation, protection shade, wash rooms, drinking water outlets, etc. all around lake and on outer circuit (round GLA circuit trek)

- Offering training to more nature and bird guides (natural and cultural interpreters)

- Formulation of an inclusive and powerful management structure, self sustaining business and revenue model of GLA with a Formulation of a tourism master plan with short term, midterm and long term actions

- Formulation and application of commonly accepted code of conduct manual

- Integrated Marketing and promotion which are based on both online and offline

Most of the aforementioned expectations are not fulfilled as tourism sector lacked priorities in terms of budget allocation and actions. This is also the weakness of this destination at present.

\section{Sustainable tourism development status, perspective and challenges of GLA}

A natural destination like GLA has immense opportunity to be developed as a popular newer destination as it is found that around $64 \%$ of total tourists arrived in Nepal in 2017 visited natural areas like national parks, conservation areas and wildlife reserves. The domestic tourists including students, families, traders, etc. are the main market segments of GLA at present where those tourists arrive for short breaks. The speedy economic growth in neighboring countries (India and China) and huge tourist market segments in Utterpradesh and Utterakhand states (that has around 230 million population) in India are opportunities for GLA to attract international tourists from the nearby market segments. The rich and diverse biodiversity, flora, fauna, and varied landscape are the key attractions for tourists who visit in very low numbers from Europe and USA. There are following actors found as directly and indirectly associated with the tourism function in GLA.

Figure 6: Tourism related existing and potential multi-stakeholders associated with GLA in making tourism sustainable Legends:

BCN = Bird Conservation Nepal, CFUGs = Community Forest Users Groups, CGLTDB = Comprehensive Ghodaghodi lake and Tourism Development Board, DMO = Destination Management Organization, GACPAFN = Ghodaghodi Area Conservation \& People Awareness Forum - Nepal, GCCSN = Ghodaghodi Cultural Conservation Society - Nepal, NTO = National Tourist Organization, and R \& R = Recreation and Research (Zoological, Eco) 


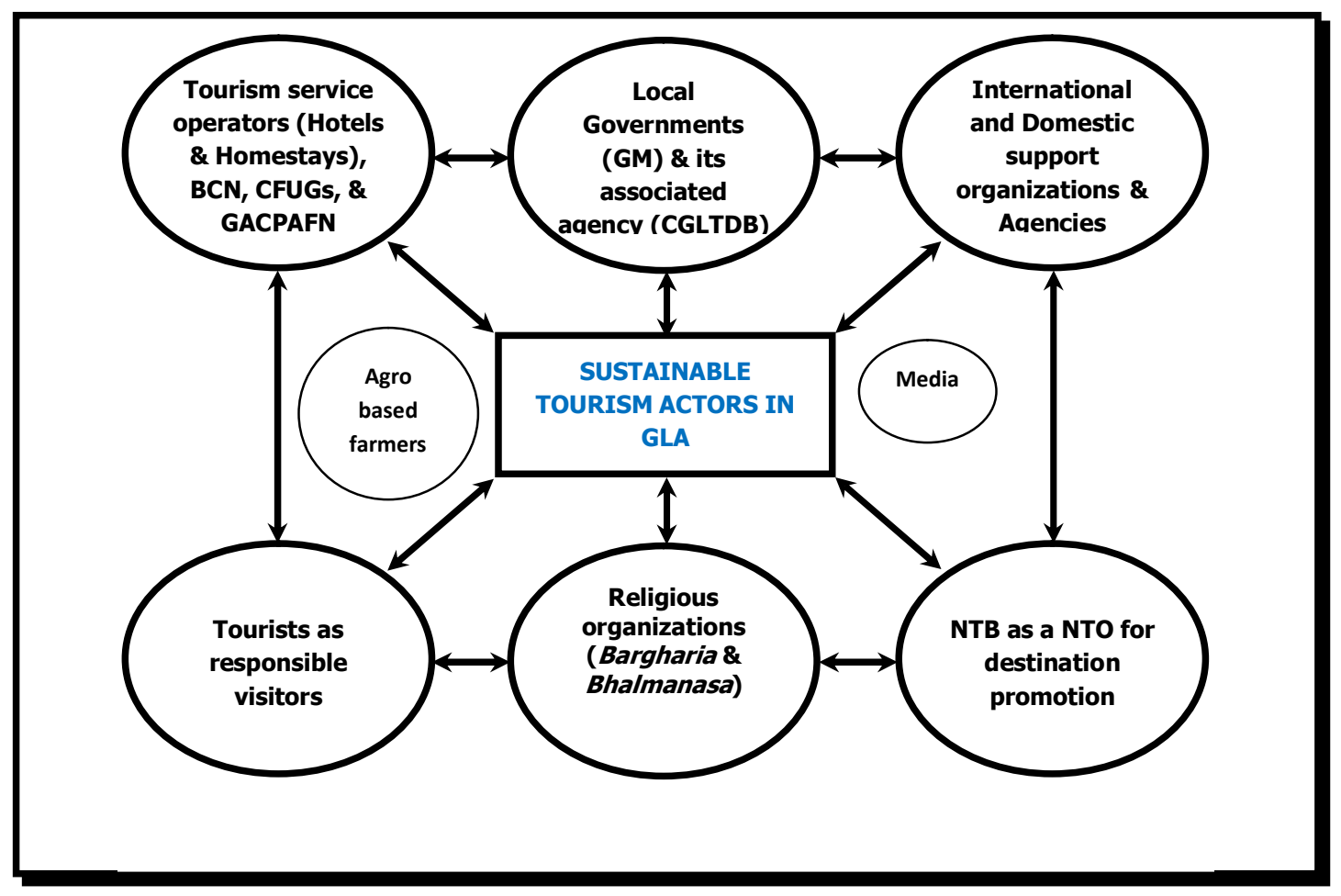

Source: Author

GM through the formal approval of the meeting of its municipal council has formulated CGLTDB in 2017 with the vision of establishing Destination Management Organization (DMO) with specialized focus on the conservation and sustainable development of tourism. GLA is surrounded by 11 community forests and their users groups. The institutional structures of community forest are wide potential for the mobilization of people, conservation, and systematic uses of forest products.

Although local peoples' education and knowledge in rural areas is very low, backward communities, ethnic groups, dalits, women and people from various caste and creeds are found to be more conscious about the potential benefits of tourism. This indicates that tourism can be well accepted by the people for its sustainability at large and it can enhance opportunities for both rural and domestic tourism. The low level of awareness among local people on tourism and its opportunities and lack of a systematic structure for the justifiable distribution of income generated by tourism around GLA are preliminary challenges for the sustainable growth and development of tourism in the area. However, the lack of conservation led tourism roadmap/master plan with the sufficient studies on the potential tourists' sites and actors, and such a road map directed strategies are the major bottlenecks for the systematic development of tourism in GLA.

\section{Conclusion}

Sustainable tourism is about making tourism economically efficient while at the same time safeguarding the environment and preserving, modernizing and promoting socio-cultural heritage sites. GLA at present does not feature prominently amongst tourism destinations in Nepal but holds a huge potential to attract visitors for sustained tourism growth through a wide range of natural and cultural attractions. However, the quality of GLA's physical destination facilities as well as its service delivery does not meet international expectations at present context and creates an unsustainable shift towards a high-volume, low value model. That is due to the lack of value added well-planned sustainable form of tourism plan and action based on realistic market analyses. As recommended by Joshi (2016) in his study for the application of sustainable and cultural model of urbanization of GM to make the municipality prosperous and unique place to visit, planed interventions for a number of activities like the development of tourism infrastructure, application of management system, conservation of biodiversity, cultural heritage and environment, institutional reform, capacity building of tourism service providers, and enhancement of the quality standards of destination are needed for the sustainable development of tourism. For it, GLA not only lacks a coherent approach to combine and co-ordinate efforts of all players to attract more visitors with higher spending capacities but also there is shortfall of a long-term, broader and meaningful participation by the local communities in the tourism system.

For the sustainable tourism development, there can be high, valuable and proactive roles of Comprehensive Ghodaghodi Lake and Tourism Development Board (CGLTDB) for the formulation of an integrated conservation and tourism development master plan with short term, midterm and long term actions and responsible management structures. The CGLTDB should play proactive role for it. As development of a sustainable tourism industry with its multidisciplinary nature is not possible by 
individuals and organization working in isolation, an integrated approach to tourism planning, development and management in close cooperation of all stakeholders with grass-root community at the core can be the best fitting to enhance sustainable tourism progress and benefits in GLA. Furthermore, it requires a leading role by GM for adopting an integrated approach in association with provincial government (Ministry of Industry, Tourism, Forest and Environment - MoITFE), central government, donor agencies, and national and international development and conservation institutions for selective tourism development interventions in GLA.

\section{Acknowledgments}

The knowledge for this publication is largely built during author's engagement with Deutsche Gesellschaft für Internationale Zusammenarbeit (GIZ), Ghodaghodi Municipality and Comprehensive Ghodaghodi Lake and Tourism Development Board as a tourism consultant and adviser in Sudurpaschim province for the formulation of tourism development master plan of Ghodaghodi Lake Area (GLA). The author would like to thank Yadav Ojha (Capacity Development Support to Governance CDSG, GIZ), Mamta Prasad Chaudhary (Mayor, Ghodaghodi Municipality), Daya Ram Chaudhary (Vice President, Comprehensive Ghodaghodi Lake and Tourism Development Board), Dr Ram Bahadur Chaudhary (socio-economic expert) and all local respondents in GLA who were the sources of knowledge and inspirations for this work.

\section{Reference}

Bhatt, D.P. (2006). Ecotourism in Nepal. Kathmandu: Anju Bhatt.

Bhatta, R. N. (2000). Tourism and the environment: A quest for sustainability. New Delhi: Indus Publishing Company. DFO. (2073). Ghodaghodi Lake Area catchment level management plan (B.S. 2069-2073). Kailali: District Forest Office (DFO).

Dhakal, D. P., Khadka, M., Sharma, S. \& Choegyal, L. (2007). Lessons learned: Nepal's experience implementing sustainable rural tourism development model. Kathmandu: Tourism for Rural Poverty Alleviation Programme. Available: http://lib.icimod.org/record/13182/files/4997.pdf

Far West (2018). About Far West Nepal. How its started? Available at https://www.farwestnepal.org/

France, L. (2006). Sustainable tourism. London: Earthscan Publications Limited.

GM. (2074). Brihat Ghodaghodi Tal tatha paryatan bikash boardko karyabidhi 2074 (Comprehensive Ghodaghodi Lake and Tourism Development Board's Work Procedure 2074). Ghodaghodi: Ghodaghodi Municipality (GM).

GM and CGLTDB (2018). Ghodaghodi tal (Ghodaghodi lake, a brochure). Ghodaghodi: Ghodaghodi Municipality (GM) and Comprehensive Ghodaghodi Lake and Tourism Development Board (CGLTDB).

Grandon, R. (2004). Agenda 21 and sustainable tourism development. Nepal Travel Trade Reporter VIII (11):16-17.

Grandon R. (2007). Nepalese Tourism: The challenges .Kathmandu: Nepal Association of Tour and Travel Agents.

Hugo, M. L. (1998). Ensuring sustainability in the tourism industry, transactions of the Royal Society of South Africa, 53:2, 295-307, DOI: $10.1080 / 00359199809520396$.

Hummel, J., Oostveen, T., and Stoer, P., editors. (2003). Sustainable tourism development in Nepal, Vietnam and LAO PAD - experience of SNV and partner organizations. Quantes: SNV Nepal, SNV Vietnam, SNV Laos and SNV.

Jafari, J. (1990). Research and scholarship: The basis of tourism education. The Journal of Tourism Studies, 1(1), 33-41.

Jafari, J. (1977). Editor's Page. Annals of tourism research, V, Special Number, October/December, p. 8.

Jafari, J. (2005). Bridging out, nesting afield: Powering a new platform. The Journal of Tourism Studies, 16 (2), 1 - 5.

Joshi, D.R. (2018). Redefining modernization and urbanization in Ghodaghodi Municipality. International Journal of Graduate Research and Review. Vol 4(1): 11-18.

Joshi, D.R. (2016). A mini research report on redefining urbanization and modernization in Ghodaghodi Municipality. Unpublished research report submitted to University Grants Commission. Sukhad: Dipak Raj Joshi.

Kailali DCC (2018). Kailali braman barsa - 2075, Ghodaghodi Tal, a brochure (Kailali Visit year - 2075 Ghodaghodi Lake, a brochure). Dhangadhi: Kailali District Coordination Committee (DCC).

Kunwar R. R. (2006). Tourists and tourism Science and industry interface. Kathmandu: International School of Tourism and Hotel Management.

MoCTCA. (2019). Nepal tourism statistics 2018. Kathmandu: Ministry of Culture, Tourism and Civil Aviation (MoCTCA).

MoCTCA. (2016). National tourism strategic plan (2015-24). Kathmandu: Ministry of Culture, Tourism and Civil Aviation (MoCTCA).

MoCTCA. (2009). Paryatan niti 2065 (Tourism policy 2009). Kathmandu: Ministry of Culture, Tourism and Civil Aviation (MoTCA).

Mowforth, M, and Munt, I. (1998). Tourism and sustainability new tourism in the third World. London: Routledge.

Nepal, S.K. (2003). Tourism and the environment perspectives from the Nepal Himalaya. Innsbruck: Himal Books and STUDIENVerlag Innsbruck-Wien-Munchen.

NPC. (2019). Pandhrau yojana arthik barsa 2076-77 - 2080/81 adhar patra (Fifteenth plan fiscal year 2076-77 - 2080/81 Baseline document). Accessed on October 28, 2019 from the website of National Planning Commission (NPC) https://www.npc.gov.np/en/category/periodic_plans

Shen, F., Hughey, K., and Simmons, D. (2008). Connecting the sustainable livelihoods approach and tourism: A review of the literature toward integrative thinking. CAUTHE 2008 Conference. 
Upadhayaya, P. K. (2019), CRAIAJ, vol. 3 (1): 41-51

STN . (2007). Sustainable tourism network. Kathmandu: Sustainable Tourism Network (STN), Nepal Tourism Board.

Timothy, D. J. and Boyd, S.W. (2015). Tourism and trails: Cultural, ecological and management issues. Bristol: Channel View Publications.

UNEP and UNWTO. (2005). Making tourism more sustainable - A guide for policy makers. Madrid: United Nations Environment Programme (UNEP) and United Nations World Tourism Organization (UNWTO).

UNWTO (2007). A practical guide to tourism destination management. Available at United Nations World Tourism Organization (UNWTO) website http://publications.unwto.org/publication/practical-guide-tourism-destination-management

UNWTO (2019).Tourism enjoys continued growth generating USD 5 billion per day. Available at United Nations World Tourism Organization (UNWTO) website http://www2.unwto.org/press-release/2019-08-29/tourism-enjoys-continued-growth-generatingusd-5-billion-day

Upadhayaya, P. K. (2011). Peace through tourism: A critical look at Nepalese tourism. Nepal Tourism and Development Review. 1(1). DOI: https://doi.org/10.3126/ntdr.v1i1.7368

Upadhayaya, P.K. (2019a). Tourism stimulated prosperity and peace in provincial destination: An appraisal of Far West Nepal. Journal of Tourism and Hospitality Education, 9, 30-39. DOI: https://doi.org/10.3126/jthe.v9i0.23678

Upadhayaya, P. K. (2019b). Sudurpashchim Pradeshko bikashma paryatan chettra ko bhumika (Role of tourism for the development of Sudurpaschim). Available: http://www.paschimtoday.com/news-details/6143/2019-08-04

Upadhayaya, P.K., and Sharma, S. R. (2010). Sustainable tourism and state building. In: Upreti, B. R.; Pyakuryal, K. N.; Sharma, S.R. and Ghimire, S., editors. 2010. The remake of a state: Post-conflict challenges and state building in Nepal. Kathmandu: Swiss NCCR (North-South) and HNRSC - Kathmandu University, 87-109. Available: https://kusoa.edu.np/wpcontent/uploads/2018/08/the remake of a state.pdf

Upreti, B. R., Sharma, S.R., Upadhayaya, P.K., Ghimire, S., and Iff, A. (2013). Making business count for peace: Reflections from tourism sector in Nepal. Kathmandu: Kathmandu University, NCCR and Swiss NCCR North-South. Available: http://www.swisspeace.ch/countries/nepal.html

Weaver, D. (2006). Sustainable tourism: Theory and practic. London: Elsevier. Available: https://www.academia.edu/34445755/Sustainable Tourism Theory and practice

Zolfani, S.H., Sedaghat, M., Maknoon, R. and Zavadskas. E.K. (2015). Sustainable tourism: A comprehensive literature review on frameworks and applications, Economic Research-Ekonomska Istraživanja, 28:1, 1-30, DOI: 10.1080/1331677X.2014.995895. Available https://www.academia.edu/10782787/Sustainable tourism_a_comprehensive_literature_review_on_frameworks_and_applications ?email_work_card=view-paper 